\title{
DIEGO DE ROJAS Y ALONSO MULEY ENRÍQUEZ Y MERÍN DE FEZ: ILUSTRES ESPOSOS DE CÁNDIDA COMPAÑERO
}

\author{
María del Carmen Ansón Calvo*
}

\begin{abstract}
Afortunadamente hoy el estudio de la minoría morisca va ocupando progresivamente más y más el tiempo de los investigadores, aunque, como ya expuse hace algunos años, interesa prioritariamente el problema de la expulsión, de sus causas y de sus consecuencias. Desde el punto de vista histórico, contamos también con algunas valiosas y próximas puestas a punto del tema ${ }^{1}$ que ayudan a ver la panorámica investigadora sobre los mismos y trabajos puntuales, cada día más fructíferos e interesantes, llevados a cabo por compañeros filólogos y arabistas que ayudan efizcamente a presentarnos una visión cada día más completa y acertada del colectivo morisco o hispano-árabe, como prefiere denominarlo nuestro gran arabista Míkel de Epalza². Ahora bien, frente a la pléyade de trabajos dirigidos a temas generales, se echan en falta aportaciones que nos presenten noticias de las familias más importantes de la minoría morisca de tierras zaragozanas, al estilo de las que se presentan para otras zonas de España o, por ejemplo, las que de forma muy documentada nos presenta periódicamente Anchel Conte para la elite oscense de los Zafar-Compañero ${ }^{3}$. Sobre la rama zaragozana de esta poderosa familia, yo misma he dado algunas noticias en mis publicaciones sobre los moriscos aragoneses y sigue incluida en mi línea de investigación. Hace algunos años también escribió sobre ella J.
\end{abstract}

\footnotetext{
* Universidad de Oviedo.

1. G. COLÁS LATORRE, «Los moriscos aragoneses: estado de la cuestión y nuevas perspectivas», VII Simposio Internacional de Mudejarismo, Teruel, 1999, pp. 215-260.

2. M. de EPAlZA, «Trabajos actuales sobre la comunidad de moriscos refugiados en Túnez, desde el siglo XVII a nuestros días», Actas del Coloquio Internacional sobre literatura aljamiada y morisca, Madrid, 1978, p. 429.

3. A. CONTE, «La rama oscense de los Compañero: Apuntes biográficos», Sharq Al-Andalus, 13 (1996), pp. 129-144 y «Nivel económico de los moriscos oscenses», VII Simposio Internacional de Mudejarismo, Teruel, 1999, pp. 299-317.
} 
Fournel-Guérin, aunque los datos y conclusiones de mis investigaciones no siempre coinciden con las publicadas por esta última autora ${ }^{4}$. Esto es lógico si las fuentes manejadas no son las mismas y, sobre todo, si las investigaciones se basan sólo en fuentes de una única tipología, frente a las que sus conclusiones proceden de datos extraídos de fuentes muy diversas, que ayudan a completar o clarificar pasajes o variables confusas, pero, a la larga, eso es, como todos sabemos, uno de los alicientes en la investigación: contrastar, dudar, discutir y conseguir entre todos la proximidad a la verdad. Junto a esta carencia de publicaciones sobre familias destacadas de la minoría morisca, también hay importantísimas lagunas sobre sus líderes, hombres y mujeres que dirigieron de una forma más o menos marcada las mentes y los cuerpos de aquellas gentes que, aterradas en muchos momentos de su triste y complicada vida por los poderes dominantes, necesitaban el apoyo anímico, personal, religioso y cultural de sus "principales", como los denominaban frecuentemente los miembros de los tribunales inquisitoriales, y de aquellos de su minoría que, por determinadas razones, estaban más cerca, o, al menos, "menos distantes" de los poderes dominantes. En esta línea me pareció sumamente interesante una aportación de la profesora María Jesús Rubiera dirigida a "descubrirnos" el origen y la larga trayectoria de los miembros de una de las familias hispano-árabes andaluzas más destacada, la de los "Muley y Merín", a la vez que motivaba la inquietud de los historiadores sobre la posible permanencia o desaparición en España de todos sus miembros tras la conquista de Granada ${ }^{5}$. A esta inquietud, y como una posible contribución que ayude a constatar alguna de las sugerencias presentadas por la Prof. Rubiera, va dirigida esta aportación, porque las noticias vertidas en su trabajo conectan ahora con algunas que yo había extraído de distintas fuentes documentales sobre los Muley Merín y que, en parte, se comentarán en esta contribución.

Distintas aportaciones, y de forma destacada la ya citada de M.J. Rubiera, parecen indicar que los Muley y Merín constituían una familia rica y poderosa, entre cuyos más destacados personajes se cita a Francisco Núñez Muley, quien en 1513 fue, con otros notables del reino de Granada, a visitar a su Alteza el Rey Católico y quien en 1566, representando a la comunidad morisca granadina, e intentando suspender la ejecución de una Pragmática que prohibía a los moriscos el uso de cualquiera de sus señas y tradiciones, elevó un Memorial al Presidente de las Reales Audiencias y Chancillerías de este reino, Memorial conocido y estudiado por distintos investigadores (Mármol Carvajal, Rubiera, Vincent, etc.), que en palabras de Barrios Aguilera "es un grito des-

4. J. FouRnEl-GuÉRIN, «Une famille morisque de Saragosse: les Compañero», Awrâq, 4 (1981), pp. 179-183.

5. M.J. Rubiera Mata, «La familia morisca de los Muley-Fez, Príncipes Meriníes e infantes de Granada», Sharq Al-Andalus, 13 (1996), pp. 159-167. 
garrado, sobrecogedor, por la justificación de la identidad cultural de su pueblo", pero que, desafortunadamente, acabó en el más absoluto fracaso ${ }^{6}$.

Ahora bien, si el Memorial de Francisco Núñez Muley es conocido y ha sido tratado por distintos estudiosos, en cambio se sabía muy poco sobre la destacada personalidad del autor del mismo y fue M.J. Rubiera quien con su artículo nos hizo su presentación en sociedad como posible miembro de la familia real nazarí, recordando que el apellido Muley es el tratamiento que recibían los reyes y príncipes descendientes de Yúsuf ben Názar, fundador de la dinastía musulmana que reinó en Granada de los siglos XIII al XV, conocido como Muley Hacen o Muley Baudili. En el citado Memorial de Francisco Núñez Muley, éste cita a una serie de familiares, como su sobrino Don Hernando Muley, hijo de Don Álvaro, o su tío Don Hernando de Fez, como procedentes de Fez, es decir, asignándoles un origen marroquí. La asociación de éstos y otros datos y la noticia recogida por B. Vincent, procedente de un documento de 1579, en la que Don Hernando Muley dice: "soy de linaje de los reyes de Fez y Marruecos, soy de linaje de los reyes", conducen a deducir el origen marroquí (Fez) y el linaje real (Merín) de esta familia y del autor del famoso Memorial $^{7}$. Esta aseveración se demuestra en un concienzudo estudio genealógico, expuesto por Rubiera en su citada aportación, en el que nos conduce hasta finales del siglo $\mathrm{XV}$, presentándonos a Don Hernando, o Fernando de Fez, tío de Nuñez Muley, casado con una hija del sultán nazarí Abu-l-Hasan (Muley Hacen o Biliacen) y por tanto cuñado de Boabdil. Debido a este hecho, y teniendo en cuenta que el vínculo cognaticio funcionaba dinásticamente en estas familias y sus mujeres transmitían los derechos al trono, Don Álvaro de Fez y su hijo Don Hernando, nieto y biznieto respectivamente de Muley Hacen, eran príncipes nazaríes e infantes de Granada. A su vez, este minucioso estudio documental, genealógico e histórico nos lleva a deducir que Fernando de Fez era, por otra parte, descendiente del último Meríní, el sultán 'Abd al Haqq ibn Abí Sa'íd, cuyo poder acabó en la revolución habida en Fez en 1465, y de la que posiblemente pudo escapar Don Fernando a Granada, donde reinaba Muley Hacen, quien le casó con una de sus hijas. Su antiguo origen es lo que motivará el que usase el título califal como sultán Meríní en el exilio, el que señale a Fez como su lugar de origen, así como el que posiblemente, al reinar en Fez la dinastía que derrocó a su padre, ésta fuera una de las causas por las que prefirió seguir en España con distintivos y privilegios propios de su rango, que acompañar a Boabdil en su exilio marroquí.

6. M. BARrios Aguilera, «El reino de Granada en la época de Felipe II», en J. Martínez Millán (dir.), Felipe II (1527-1598). Europa dividida: La monarquía católica de Felipe II, Madrid, 1998, tomo III, p. 63.

7. Citado por M.J. RUBIERA, op. cit., pp. 159-160 y B. VINCENT, «La familia morisca», Moriscos y marginados en la España del siglo XVI, Granada, 1987, p. 22. 
Ahora bien, don Fernando de Fez y su sobrino Núñez Muley no debieron de ser los únicos miembros de la familia real nazarí que quedaron en España y, entre los que cita M. J. Rubiera, me parece interesante señalar a un nieto de Fernando de Fez, don Hernando de Mendoza de Fez Muley, que en 1561 estaba casado con Florencia Enríquez Çaybona, así como el prestar atención a la larga enumeración de apellidos típicamente moriscos y, señaladamente, de su aristocracia, que recopila esta autora. De hecho, fue precisamente la aparición de estos apellidos ensamblados en una misma persona, Alonso Muley Enríquez y Merín de Fez, lo que me llamó la atención, pues deduzco que también este Muley Merín era descendiente de la dinastía Meríní, (¿quizás hijo del matrimonio de Hernando de Mendoza de Fez Muley y Florencia Enríquez?) y, lo que parece más interesante, el hecho de encontrarlo, según constato en distintos documentos, muy lejos de tierras andaluzas, en la capital del reino aragonés, en Zaragoza. Por otra parte, el apellido Enríquez también parece que va asociado a familias moriscas de vieja raigambre e importancia en otros lugares de Andalucía ${ }^{8}$. Así, pues, ante estas informaciones, parece oportuno dar a conocer un dato curioso y es el que en documentación eclesiástica y notarial aragonesa, así como en algunos documentos inquisitoriales, aparece citado un rico y destacado morisco, calificado siempre como tal, con el título de Don y, muy frecuentemente, como caballero, llamado Alonso Enríquez Muley y Merín de Fez, u otras veces Alonso Muley y Merín Enríquez de Fez, procedente de Sevilla, y afincado y avecinado en la ciudad de Zaragoza en los primeros años del siglo XVII. Por otra parte, su procedencia sevillana quizá pudiera conectarse con las noticias dadas por Domínguez Ortiz y recogidas por B. Vincent en un artículo suyo, en el que cita a Hernando Muley y a Andrés Muley, posiblemente expulsados de Granada, como principales cabezas de un complot descubierto en Sevilla en $1580^{\circ}$. ¿Sería mucho aventurar que algunos miembros de los Muley, tras la revuelta granadina, se afincaran en Sevilla y de este grupo familiar procediese el citado D. Alonso Muley que encontramos viviendo en tierras aragonesas?

Según pudimos deducir de nuestra investigación, la razón del nuevo lugar de residencia de D. Alonso Muley y Merín Enríquez de Fez fue el haber contraído matrimonio con una riquísima zaragozana, miembro de una de las familias moriscas de mayor importancia social, económica y cultural de Aragón. Se trata de Cándida Compañero Navarro, hija del poderoso morisco Enrique Compañero y de su acaudalada mujer, y conocida morisca, Gracia Navarro, y

8. J. CASTILLO, «Hidalgos moriscos: Ficción histórica y realidad social. El ejemplo del linaje Enríquez Meclín de la Tierra de Baza (siglos XV-XVIII)», Mélanges Louis Cardaillac, Zaghouan, 1995, pp. 162-180.

9. B. VINCENT, «Et quelques voix de plus: de Francisco Núñez Muley à Fátima Ratal», Sharq AlAndalus, 12 (1995), p. 138, cita a A. Domínguez ORTIZ, «Desventuras de dos moriscos granadinos», Homenaje a Jacinto Bosch Vilá, Granada, 1991. 
hermana del otro hijo de este matrimonio, Miguel Enrique Compañero, morisco que en los primeros años del siglo XVII, heredero del papel que habían ostentado sus predecesores, y en especial su tío paterno, Juan Compañero, será considerado entre los suyos como "el reyezuelo de los moriscos aragoneses". Este "honor" le ocasionará a él y a los suyos no pocos infortunios con el poder civil y el religioso, hasta caer en una red de acusaciones, secuestros de bienes, juicios y castigos inquisitoriales, que le conducirán a ser procesado y ejecutado el año 1608 en un Auto de Fe celebrado en Zaragoza, infortunio que sufrirá también con él su joven esposa y que motivará la orfandad de sus cinco hijos de corta edad, que pasarán a ser tutelados por su abuelo materno y por la hermana de su padre, su tía Cándida Compañero, la morisca con quien hemos señalado había contraído matrimonio Don Alonso Enríquez Merín y Muley de Fez ${ }^{10}$.

La importancia y el destacado lugar económico y social que la familia Compañero tenía entre los moriscos aragoneses era conocida y aceptada dentro y fuera de nuestras fronteras, llegando a ser muy considerada entre las elites, no sólo de España, sino de Fez, Argel y de otros lugares lejanos. Algunos de sus miembros viajaban con frecuencia lejos de nuestro país e incluso llegaron a ocupar cargos destacadísimos en Fez y en Argel, como Juan Zafar, primo y tío de Cándida Compañero, y sus redes comerciales se extendían a lugares muy distantes de su residencia zaragozana. En cuanto a su riqueza, es casi imposible hacer una enumeración o valoración que se aproxime a la realidad, pues los Compañero tenían bienes agrarios, ganaderos, empréstitos, arriendos de grandes propiedades hasta de las Órdenes Militares y del mismo duque de Lerma, extendidos por tierras oscenses, de donde procedían en su origen, y por tierras zaragozanas, amén de grandes negocios de muy distinta tipología dentro y fuera de nuestro país, y de bienes inmobiliarios en distintos lugares de Aragón. Para señalar tan sólo su riqueza inmobiliaria en la capital de Aragón, en la ciudad de Zaragoza, donde prioritariamente los encontramos residiendo en la segunda mitad del siglo XVI, baste citar que en la tasación de bienes de los moriscos expulsos, que se mandó hacer tras su expulsión de tierras aragonesas, se hizo un recuento de las casas y huertas cercanas a la ciudad que poseían en Zaragoza, y esta familia era la mayor propietaria de casas y una de las más destacada en propiedades rústicas ${ }^{11}$. No obstante hay que hacer constar que esta documentación no da ni una idea aproximada de su inmensa riqueza, repartida por muy distintos lugares de Aragón, según hemos constatado en la documentación notarial ${ }^{12}$. Es oportuno hacer este inciso sobre la riqueza e im-

10. M.C. Ansón CAlvo, Banco de Datos particular de Actas Sacramentales. A(rchivo) P(arroquia) $\mathrm{S}($ an) $\mathrm{P}$ (ablo) Z(aragoza).

11. A(rchivo) H(istórico) Not(arial) Z(aragoza), Notario Diego Fecet, 17 junio 1611, fols. 785 -786.

12. M.C. ANSÓN y P. GAY, «Las familias moriscas expulsadas de Zaragoza: un análisis de su número y propiedades», Actes du VII Symposium International d’ ̈̈tudes Morisques sur Famille Morisque: Femmes et enfants, Zaghouan, 1997, pp. 72-91. 
portancia que tenía la familia Compañero en el contexto morisco aragonés, para ayudar a comprender el que un morisco tan destacado, por su origen, su rango y, posiblemente, su riqueza, como Don Alonso Merín Muley de Fez se desplazara desde tierras andaluzas hasta Aragón para elegir esposa.

Como hemos podido deducir a través del estudio de una serie de documentos, creo que inéditos y de los que en esta publicación se da la primicia de sus datos, Cándida Compañero Navarro era feligresa de la zaragozana parroquia de San Pablo, en cuya área urbana se encontraba La Morería, y donde vivía en una espaciosa casa de su propiedad, situada en la mejor zona de la misma, en la Plaza de la Alfóndiga. Con fecha 16 de febrero de 1604 encontramos un acta sacramental de matrimonio en el Libro de casados de la Parroquia de San Pablo, en la que se recoge el matrimonio celebrado entre "Cándida Compañero Navarro, feligresa de dicha parroquia, con Don Alonso Enríquez Muley y Merín de Fez, residente en Sevilla, y de profesión abogado $^{13}$. En este acta matrimonial nada se dice del estado civil del novio, pero sí se hace constar que la contrayente era viuda. Esta noticia la hemos podido corroborar, pues en nuestro Banco de Datos de Bautismos, Matrimonios y Difuntos de los Parroquianos de San Pablo del siglo XVII, encontramos el acta de casados del primer matrimonio de Cándida Compañero, matrimonio que, por la importancia de quien fue su primer esposo y para compensar algunas carencias y errores vertidos en otros trabajos de investigación sobre esta familia, parece oportuno recoger aquí.

La morisca zaragozana Cándida Compañero, aunque nacida en el seno de una familia rica y considerada, pasó una infancia durísima. Huérfana desde muy pequeña de padre, le faltó también el calor y la compañía materna, porque su madre, Gracia Navarro, siendo muy joven, fue acusada por la Inquisición, junto con sus hermanas, Ana y María y sus cuñados, Cándida Compañero mayor, Juan Compañero y Jerónimo Zafar, de ser fiel a la religión de Mahoma, de practicar sus ritos y creencias, de enseñarlos a los suyos y, lo que era mucho peor, de poseer libros moriegos y de leerlos a sus "correligionarios", cosa que según sus acusadores "lo hacía mejor que un alfaquí", señalándonos así su formación cultural y religiosa. Todas estas acusaciones le valieron a Gracia Navarro ser desposeída de sus bienes y ser llevada a distintas cárceles inquisitoriales, prioritariamente a las de Logroño y Zaragoza, en algunas de las cuales le "acompañaron" sus hijos, Miguel Enrique y Cándida, cuando contaban tan sólo ocho y diez años de edad. La "obligada" ausencia de su madre y la carencia de los cuidados y afectos maternos tampoco pudo suplirlos Cándida con la presencia de otros familiares porque, desafortunadamente para nuestra niña morisca, tanto sus tías como otros familiares próximos compartían la misma suerte que su madre y estaban también presos por la Inquisición. Ella

13. A.P.S.P.Z., Libro de Casados, año 1604. 
misma vivió en las cárceles de niña y de adolescente y, a pesar de considerar que no se le podía castigar extremadamente, porque las creencias y costumbres moriegas "se las habían enseñado su abuela y su madre siendo muy niña", la encontramos, al igual que a su hermano, incomunicada en la cárcel y vistiendo hábito vergonzante, cuando no alcanzaba los diecisiete años. Así, pues, puede decirse que, según hemos podido deducir de la documentación notarial e inquisitorial, Cándida Compañero estuvo en el punto de mira de la Inquisición "desde su más tierna infancia" y no dejó de estarlo a lo largo de su penosa y desafortunada vida ${ }^{14}$. No obstante, parece que el poder de su familia y los generosos y quizás "forzosos" donativos, propiciaron en su complicada existencia algunos breves intervalos de paz, que le permitieron contraer matrimonio por dos veces. La primera, anterior a su enlace con D. Alonso Merín, fue con otro destacadísimo personaje morisco, del que hemos buscado información y, a pesar de las muchas dificultades para conseguirla, esperamos tener la fortuna de completarla en el futuro con el hallazgo de más documentación sobre el mismo. Se trata de Don Diego de Rojas, con quien encontramos que se amonestó en la parroquia zaragozana de San Pablo el 26 de enero de 1592. Es interesante señalar que en el Acta de matrimonio se hace constar que la novia era feligresa de la zaragozana parroquia de San Pablo y el novio, Diego de Rojas, procedía de Valdepeñas (Castilla), y era "contador del marqués de Santa Cruz". Este primer matrimonio de la rica morisca zaragozana Cándida Compañero nos ha conducido a la búsqueda y venturoso hallazgo de algunas fuentes documentales, que nos permiten vislumbrar que el poder económico del contrayente estaba "casi" en consonancia con el de la novia, como se deduce por ejemplo de las Capitulaciones matrimoniales de ambos y comprobar, una vez más, la política matrimonial morisca de, al menos, "entre iguales", o como medio de ascender en su comunidad, así como deducir que el esposo de su segundo matrimonio, Don Alonso Merín, era también persona relevante en muchos aspectos, como lo había sido el primero, Don Diego de Rojas ${ }^{15}$. Por ello, y porque es una figura todavía no "suficientemente conocida", y de cuyo matrimonio con una Compañero creo dar ahora la primicia, parece oportuno hacer una semblanza de Diego de Rojas, partiendo de los datos con que podemos contar hasta el momento y en la creencia de que el cruce de informaciones procedentes de fuentes muy diversas puedan conducirnos, si no a la "total" realidad, sí quizás acercarnos a ella.

14. A(rchivo) H(istórico) N(acional) M(adrid), Sección Inquisición, Libros 327, 328, 333, 964, 965, 988, 989, 990 y 991.

15. A.H.Not.Z., Notario Martín Español, Leg. 572, año 1592. 


\section{DIEGO DE ROJAS:}

\section{PRIMER ESPOSO DE CÁNDIDA COMPAÑERO-MENOR*}

En la documentación eclesiástica, notarial, municipal y documentación privada aragonesa consultada, la primera noticia sobre el matrimonio entre Diego de Rojas, procedente de Valdepeñas y de profesión contador del marqués de Santa Cruz, y Cándida Compañero Navarro, procede, como ya hemos señalado, del Libro de Casados del Archivo parroquial de la iglesia zaragozana de San Pablo. En él consta que los amonestó, con licencia del Señor Oficial, y los desposó por palabras de presente, el Vicario de dicha parroquia, D. Gregorio de Andía, el 26 de enero de 1592. Actuaron como testigos del acto el tío paterno de la novia, Juan Compañero, D. Juan Borau y mosén Catalán, sacerdote de la misma parroquia de San Pablo. La misa nupcial se celebró un tiempo después, posiblemente por cuestiones eclesiásticas (no celebración de bodas en determinados tiempos litúrgicos, etc.), el día 26 de abril en la iglesia zaragozana de El Carmen, perteneciente al área parroquial de San Pablo. El ministro celebrante fue D. Gregorio de Andía, el mismo que lo sería en su segundo matrimonio, y fueron testigos Juan de Borau y Rodrigo Argüello, ambos secretarios del Santo Oficio, posiblemente debido a que la novia desde hacia varios años sufría castigos y prisión inquisitorial y un tiempo estuvo bajo la tutela de D. Juan Borau ${ }^{16}$.

Después de esta noticia encuentro algunas otras sobre "los Rojas" en la bibliografía y también en la documentación inquisitorial. El ensamblaje y estudio de todas ellas puede llevarnos hacia una vertiente que, quizás, conduzca a trazar algunos apuntes, que no damos como totalmente fidedignos ni definitivos, sobre Don Diego de Rojas. En principio, lo que sí llamó nuestra atención es el hecho de que, siendo contador del Marqués de Santa Cruz y residente en Valdepeñas, eligiera como esposa a una morisca vecina de la lejana ciudad de Zaragoza y, especialmente, el que ésta fuera miembro de una de las familias moriscas más destacadas y acaudaladas, no sólo de la ciudad, sino del reino de Aragón e incluso de fuera de éste. De ahí, pues, el interés por buscar más datos sobre el evento y sobre sus contrayentes. Así, tras conocer que a Don Diego de Rojas y a Cándida Compañero se les amonestó en la parroquia zaragozana de San Pablo el 26 de enero de 1592 y que, posteriormente, se celebró su misa nupcial el día 26 de abril en la iglesia zaragozana de El Carmen, como ya hemos citado, intenté localizar más noticias sobre los contrayentes en distintos

\footnotetext{
* El apelativo de menor se incluye para diferenciarla de su tía paterna, Cándida Compañeromayor, pues la coincidencia de nombre y apellidos en ambas ha dado lugar a errores en otras publicaciones. Dado que conocemos los apellidos de sus padres, citaremos como Cándida Compañero Navarro o Cándida Compañero-menor a la morisca estudiada en esta aportación.

16. A.H.N.M., Sección Inquisición, Libros 964 y 965.
} 
archivos y la búsqueda fue en parte afortunada. Así, localicé un documento que podría calificarse de vital importancia por su contenido y por los usos y costumbres que de él se deducen. Se trata de las Capitulaciones Matrimoniales de ambos, un documento muy interesante y peculiar desde un punto de vista jurídico y cuyo texto es de sumo interés por sus informaciones económicas, sociológicas, etc., y para aclarar algunos errores publicados sobre Cándida Compañero. Contiene noticias sobre las aportaciones económicas de ambos contrayentes, las disposiciones legales a las que ambos deben atenerse, siempre respetando y siguiendo las disposiciones del Fuero del Reino de Aragón por parte de ambos, pero muy especialmente recordado para el varón, como se repite en su texto, así como algunas disposiciones especiales para el caso del usufructo de bienes en caso de viudedad, una variante legal muy a tener en cuenta, dada la singularidad que sobre ella presenta la foralidad aragonesa y que, en este caso, no se quiere obviar, posiblemente por ser el novio "de Castilla" y no aragonés como lo era la novia. El documento también presenta otras singularidades interesantes dentro del campo de estudio de las mentalidades y de la muy discutida y nunca bien comprendida asimilación e integración del morisco en la sociedad española del momento ${ }^{17}$.

El matrimonio de Diego de Rojas y Cándida Compañero Navarro fue concertado entre el contrayente y los familiares más próximos de la novia, que, huérfana de padres, serán sus tíos, el riquísimo y destacado morisco Juan Compañero y su esposa, otra acaudalada e importante morisca hermana de su madre, Ana Navarro, ambos residentes en la ciudad de Zaragoza, en el área urbana de La Morería de la parroquia de San Pablo, y su único hermano, el también destacado y riquísimo morisco zaragozano Miguel Enrique Compañero. Todos ellos, según se hace constar en el inicio del documento, aceptaron las Capitulaciones del matrimonio "con voluntad, presencia y expreso consentimiento".

Don Diego de Rojas trae "en ayuda y contemplación del matrimonio todos sus bienes, muebles y raíces, censos, juros y actiones suyos en donde quiere sitios y estantes, los quales quiera haber a el pertenecientes". Además de ello, trae en dinero contado la suma de 6.000 ducados y la promesa de traerse al Reino de Aragón joyas y piezas de oro y plata y alhajas de casa que él posee.

Por su parte, Cándida Compañero, "en ayuda y contemplación del presente matrimonio", trae todos sus bienes muebles y sitios, censales, treudos, derechos, acciones habidas y por haber. Después de esta enumeración, se van citando de forma pormenorizada las aportaciones de una serie de buenas casas, algunas con horno, sitas en la zona de La Morería de la parroquia de San Pablo y otras en el área de la parroquia de San Gil que, como dato interesante, consta que sus censos se daban unos al Vicario de la parroquia de San Miguel, otros

17. A.H.Not.Z., Notario Martín Español, Leg. 572, año 1592. 
para los pobres de la parroquia de La Seo y, otros, los derivados de tres grandes casas de la calle del Serón, al Hospital del Carmen, sito en las proximidades de su propia casa y, por tanto, perteneciente al área urbana y parroquial de San $\mathrm{Pablo}^{18}$. A este respecto es interesante constatar que la aportación de estas diferentes casas a su matrimonio por parte de Cándida Compañero es lógica, si tenemos en cuenta que en un trabajo sobre la riqueza de los moriscos zaragozanos expulsados, al contabilizar y valorar las casas propiedad de los moriscos, encontramos que de las 124 contabilizadas el 37,1 por ciento de ellas pertenecía a la familia de Cándida Compañero ${ }^{19}$. Además, de la valoración conjunta del total tras la expulsión, el 35,31 por ciento correspondía a esta familia, con un monto de casi 14.000 libras (valor muy inferior al real, si seguimos la pista de sus valoraciones en distintos documentos hasta el momento de la expulsión). Ahora bien, lo más interesante para nosotros es constatar que las casas que aporta Cándida Compañero a su matrimonio son las que se citan también como de su propiedad en el documento mandado hacer por designación real en junio de 1611, a fin de evaluar los bienes de los moriscos "para tratar de vender y disponer de las casas de dichos moriscos que hay en la presente ciudad de Zaragoza". Además, según hemos podido deducir de documentación procedente del archivo parroquial de San Pablo, Cándida Compañero habitaba en una de las casas que cita en primer lugar como aportación a su matrimonio ${ }^{20}$. Era una casa sita en el centro de la Morería de San Pablo, en la Plaza de la Alfóndiga, con su horno y bastante espaciosa, próxima a las de su hermano y de su tío Juan Compañero y que debía de ser una casa importante en el contexto de las de su época, pues en el documento citado se le da una valoración de 900 libras, valoración que sólo alcanzaron el 4,8 por ciento de las casas tasadas, aunque está bastante lejos de la adjudicada a la que habitaba su hermano, la de mayor precio, 2000 libras ${ }^{21}$. Además de estas casas y otras sitas en las calles del Serón, Fustería etc, aporta también a su matrimonio una viña, un olivar, "oro y plata y alhajas de casa por valor de 5.000 sueldos" y otros muchos bienes de distinta tipología. En total, parece que lo aportado por Cándida Compañero ascendía a la alta cifra de unos 70.000 sueldos. Era lo que le correspondía de la mitad de la herencia de sus padres (compartida con su único hermano, Miguel Enrique Compañero), según se desprende de la sentencia arbitral hecha a sus tíos Juan Compañero y Ana Navarro, quitándoles la tutela de sus sobrinos, precisamente en enero de este mismo año 1592 en que contrae matrimonio Cándida y que bien pudiera ser ésta la razón de la sentencia arbitral, para repartir la herencia entre los dos herma-

18. M.C. Ansón Calvo, "Callejero de la Parroquia de San Pablo de Zaragoza», Cuadernos de Zaragoza, 19 (1975).

19. M.C. ANSÓn y P. GAY, op. cit., pp. 84-87.

20. A.P.S.P.Z., Banco de Datos particular.

21. M.C. Ansón y P. GAY, op. cit., p. 85. 
nos Compañero ${ }^{22}$. De hecho, en las Capitulaciones matrimoniales se cita dicha Sentencia y se hace alusión a ella cuando Cándida Compañero y Diego de Rojas aceptan la cifra de 70.000 sueldos jaqueses como, según dicha Sentencia, le correspondía a Cándida por herencia. Tras esta aceptación, Cándida Compañero promete renunciar a cuantos bienes de sus padres y de su tía materna María Navarro le puedan pertenecer y "ninguna otra cosa alguna le pueda ya pertenecer ni solicitar de los bienes de su hermano". Se hace constar que estos 70.000 sueldos los recibirá la contrayente "cuando oiga misa nupcial el matrimonio", señalando así el valor contractual que para ellos tenía esta ceremonia o el sacramento en sí. También se recoge el pacto de que todos los bienes muebles y sitios que adquiera la contrayente por muerte de "alguno de sus deudos" serán considerados herencia suya y de los suyos.

Por especial pacto entre partes, según se hace constar, se acuerda que Diego de Rojas asegure a su futura mujer y esposa por firma y dote, "según Fuero del presente Reino", 10.000 sueldos en moneda jaquesa, los cuales confirma y asegura sobre su persona y todos sus bienes habidos y por haber para que, en caso de disolución de matrimonio, puedan Cándida Compañero o sus herederos sacar estos 10.000 sueldos de los bienes de Diego de Rojas.

Es interesante señalar que el derecho de viudedad y usufructo de bienes de los esposos en caso de fallecimiento de alguno de ellos, tan peculiar e interesante en la legislación aragonesa, es, en el caso de este matrimonio, un tanto singular, posiblemente porque los Compañero consideraron que, dado que Diego de Rojas no era aragonés, éste podría acogerse a la legislación castellana. Ante esta desigualdad, que podría llevar en caso de viudedad a que los derechos adquiridos "favorecieran más" al esposo que a la esposa, intentaron aclarar la posición de ambos. Posiblemente a ello se deba el que en los Capítulos Matrimoniales se hace constar la renuncia de Cándida Compañero a "su derecho de viudedad" en los bienes sitios de su marido, en caso de que le sobreviviese, así como la renuncia a las "ventajas forales" y partición de bienes muebles, tanto de los traídos como de los adquiridos durante el matrimonio, y solamente sacará en ayuda de su matrimonio los dichos 5.000 sueldos que trae Diego de Rojas en oro, plata, muebles y alhajas de casa, todos sus vestidos, arreos y joyas de su persona y los dichos 10.000 sueldos de dote, así como la cuarta parte de los bienes del dicho Diego de Rojas, en caso de que muera sin hijos legítimos, y la octava parte de los dichos bienes, si muere con hijos legítimos. Se dice que esto se hace para compensar el derecho de viudedad y otros derechos a los que la contrayente renuncia. De igual forma es pactado que Diego de Rojas, si sobreviviese a su mujer, renuncie al derecho de viudedad y a las ventajas forales y partición de bienes, etc., que pudiera tener, y también se compensa su renuncia y se pacta que pueda sacar de su mujer, si ella ha muer-

22. A.H.Not.Z., Notario Miguel Español, Leg. 1525, año 1592. 
to "dejando hijos o hijos de hijos" la cuarta parte de los bienes que se dice ha de sacar si sobreviviere a su marido y, si ella muere sin hijos o hijos de hijos, tome su marido la mitad de todos los bienes de Cándida Compañero. En este sentido, se pacta también que los bienes, o títulos lucrativos, que cualquiera de las partes adquiera serán para su propia herencia y de los suyos.

Para "resguardar" a la mujer, se pacta también que Diego de Rojas, "durante su matrimonio, no pueda vender, ajenar, ni empeñar" el ajuar, ropa, vestidos y joyas de Cándida Compañero sin consentimiento de ella, "renunciando así al Fuero que contra ello dispone". Es decir, en todo el documento parece que la familia de la novia va haciendo uso o desuso del Fuero aragonés según conviene a la contrayente y así parece deducirse cuando se apostilla que "los presentes Capítulos se han de reglar y ordenar según el Fuero del Reino de Aragón en aquellas cosas que no está dispuesto y ordenado en los presentes Capítulos". Es decir, es el esposo quien va aceptando las normas que se le imponen. A este respecto me parece muy interesante señalar que en lo pactado "entre partes" se exige a Diego de Rojas que "sea tenido y obligado a venir y que vendrá y habitará en el presente Reino de Aragón, en la presente ciudad de Zaragoza o en aquella ciudad y lugar que le pareciere bien visto en el presente reino" y se le exige que debe hacerlo "dentro del tiempo de seis meses, contaderos desde el día de la jura de estos Capítulos", así como el que debe de venir con toda su hacienda y casa y que vestirá y enjoyara a su esposa. Otra cláusula importante es la promesa de que el contrayente "no sacará a su esposa ni a su hacienda contra su voluntad a vivir fuera del Reino de Aragón" y me parece interesante porque habitualmente se ha tenido la percepción de la mujer morisca con un alto grado de sumisión, de seguimiento al marido, mientras que en estas Capitulaciones se refleja claramente que no es así, sino que más bien se le exige al marido una serie de condiciones que inciden fuertemente en su vida. Así, aparte de su aportación económica, nada despreciable, pero lejos de la llevada por la novia al matrimonio y la de sus valiosas joyas y alhajas e importante dote, se le exige que renuncie a las ventajas legales que el Fuero de Aragón podía depararle y frente a la idea tradicional de que sea la mujer la que siga a su esposo, es a él, el hombre que debe de mantener su casa y sus hijos, según se aceptaba en aquella sociedad y hasta hace pocos días en la nuestra, el que debe de cambiar su residencia, abandonar Valdepeñas, donde gozaba de un cargo importantísimo, el de contador del Marqués de Santa Cruz, con los privilegios, emolumentos y prestigio que ello conllevaba y, abandonando todo, venir a residir a tierras aragonesas en un breve lapso de tiempo, en seis meses, tras la firma de estas Capitulaciones, que fueron firmadas por Diego de Rojas, Cándida Compañero, su tío Juan Compañero y su hermano Miguel Enrique Compañero. Tras firmarlas, juraron "los cónyuges futuros" sobre la Cruz y los Cuatro Evangelios de tomarse por marido y mujer como lo manda la Santa Madre Iglesia. El documento, rubricado por Martín Esteban y Luis Martín Español, escribientes residentes en Zaragoza, debo señalar que está escrito en un tipo de letra cursiva distinto al de la aceptación del mismo. 
Tras estas noticias sobre la boda y Capitulaciones matrimoniales, no sabemos ciertamente qué derroteros llevó el matrimonio de Diego de Rojas y Cándida Compañero. Es una investigación para nosotros no terminada y que esperamos que nuestra intensa búsqueda de datos en distintas fuentes documentales nos ayude a descifrar lo que constituye parte importante de un puzzle en nuestra investigación sobre los Compañero y sobre los moriscos aragoneses. Desde luego, es un hecho curioso el que en la búsqueda hecha en nuestro Banco de Datos, construido hace casi treinta años a partir de las actas de bautismos, matrimonios y defunciones habidos en los siglos XVI y XVII en la parroquia zaragozana de San Pablo, donde se ubicaba La Morería, en una de cuyas calles vivían los Compañero, no hayamos vuelto a encontrar noticia alguna de la vida o de la muerte de Diego de Rojas, ni tampoco de sus posibles descendientes, pues ningún niño con su apellido se recoge en los Libros de Bautismos ni de Defunciones. Tampoco hemos sido más afortunados en posibles hallazgos derivados de documentación notarial, donde, dada la riqueza del matrimonio y la copiosa documentación que ante distintos notarios generó la familia Compañero y la propia contrayente (compras, ventas, apeos, arriendos, préstamos, donaciones, etc., etc.), parecía lógico que la presencia de Diego de Rojas y su vida profesional se reflejase en la documentación de la época. Todo me lleva a pensar que, posiblemente, la cláusula de las Capitulaciones que exigía a Diego de Rojas cambiar en seis meses su lugar de residencia, dejar Valdepeñas y venirse a vivir con su esposa a Aragón, no debió de cumplirse. Posiblemente el alto cargo que tenía y los emolumentos y privilegios derivados del mismo, pudieron influir para no iniciar su andadura hacia tierras aragonesas. Ahora bien, para cualquier historiador, aunque conozcamos por nuestras investigaciones la movilidad geográfica de los moriscos, en especial la de aquéllos que pertenecían a las elites, pues creo que no se ha estudiado todavía en profundidad el mundo diferenciado y diferente de quienes componían los distintos estratos de "la sociedad morisca", no puede dejar de mover nuestra curiosidad el hecho de que un morisco de Valdepeñas viniera a desposarse con una morisca zaragozana. Ahora bien, la elegida era una "pieza valiosa" desde todos los puntos de vista, pues no debemos olvidar que, además de su posición económica, era de la más alta consideración entre los suyos, hermana de quien se calificó como "reyezuelo de los moriscos aragoneses", una mujer culta y desde luego conocedora y amante de las tradiciones y esencias de los suyos, pero también una mujer que ya había sufrido penas inquisitoriales y residido en sus cárceles. Esto nos lleva a preguntarnos ¿quién era este morisco, que podía llegar a emparentar con una de las familias moriscas aragonesas de mayor raigambre e importancia? Sabemos poca cosa de él. Su nombre y primer apellido y el que su padre se llamaba Miguel, según se reseña en su acta de matrimonio, así como que residía en Valdepeñas y era contador del Marqués de Santa Cruz.

La conexión de Diego de Rojas con Valdepeñas, nos lleva a recordar que este lugar, muy próximo a otros de numerosa población morisca, como Dai- 
miel y Almagro, aglutinaba una importante comunidad morisca, que se vio incrementada tras el problema granadino de 1568 con una considerable aportación de cristianos nuevos ${ }^{23}$. Valdepeñas pertenecía a D. Álvaro de Bazán, I Marqués de Santa Cruz (1526-1588) desde 1581 y, antes, si consideramos que ya en 1575 D. Álvaro había adelantado para su compra 54.000 ducados, pero las controversias con el pueblo de Valdepeñas, cuyos vecinos optaban también a su adquisición, demoró la adjudicación a Álvaro de Bazán hasta 1581, aunque éste siempre contó con el apoyo de Felipe II, quien le había concedido el marquesado en agradecimiento a los servicios prestados en distintos escenarios bélicos durante su reinado. Por otra parte, no debe olvidarse que Felipe II no sólo distinguió a D. Álvaro de Bazán con el marquesado y la ayuda para la adquisición de Valdepeñas, sino que en 1571, tras su decisiva intervención en la batalla de Lepanto, le entregó las Encomiendas de La Solana y la Alhambra, pertenecientes antes a la Orden de Santiago, adquisición muy importante, si consideramos que D. Álvaro tenía sus dominios señoriales en el Campo de Montiel, entre la Solana y La Alhambra, casi anexos a estas Encomiendas y en la cercana zona de El Viso, comprada también a Carlos I, donde se había hecho construir la casa-palacio, sede de su marquesado, el magnífico palacio de El Viso del Marqués, hoy sede del Archivo de la Marina. Ahora bien, estas Encomiendas pertenecieron a la Orden de Santiago y, Valdepeñas y El Viso, a la de Calatrava ${ }^{24}$.

Todas estas noticias no vienen sino a confirmar una vez más la importancia que parece debía de tener el ser contador del Marqués de Santa Cruz. Diego de Rojas sabemos que lo era en el año 1592, año en el que ostentaba el marquesado el hijo del gran insigne marino de Lepanto, de las campañas italianas y de las Azores y cuya muerte acaecida en Lisboa en febrero de 1588 le privó de batirse contra Inglaterra. Es decir, en 1592 estaba ocupando el marquesado su hijo, D. Álvaro de Bazán, II Marqués de Santa Cruz, de quien era contador Diego de Rojas. Hasta el momento tenemos escasas noticias sobre la familia y sobre la persona de Diego de Rojas, quizás señalar que el apellido de Rojas lo encontramos citado en distintos pasajes de una muy interesante obra de Gómez Vozmediano ${ }^{25}$, lo que parece señalar el afincamiento de los Rojas en esta zona de Almagro y de Valdepeñas y que nos consta como conta-

23. M.F. Gómez Vozmediano, Mudéjares y moriscos en el Campo de Calatrava (Siglos XV-XVII), Ciudad Real, 2000, pp. 80, 137, 139 y J. López-SALAZAR, Valdepeñas, 1752, Madrid, 1994, pp. 9, 48.

24. J.C. Vizuete MendozA, «Los regulares en el territorio castellano de las Ordenes militares (siglos XV-XVIII)», Las Órdenes Militares en la Península Ibérica, II, Cuenca, 2000, pp. 21-42; J.I. RUIZ RodrígueZ, Las Órdenes Militares castellanas en la Edad Moderna, Madrid, 1991, pp. 31, 38, 62; M. LAMBERT-GORGES, «L'Apport des Ordres Militaires à la construction de l'État Moderne dans l'Espagne des XV-XVII siècles», Las Órdenes Militares en la Península Ibérica, II, p. 1695; M.F. GÓMEZ VOZMEDIANO, «Devociones religiosas colectivas y conversiones en Almagro», Hispania Sacra, 101, 1 (1998), pp. 67-68.

25. M.F. GÓMEZ VOZMEDIANO, op. cit. 
dor del marqués en algunos documentos existentes en el Archivo Diocesano de Toledo y en el Archivo Provincial de Protocolos de Ciudad Real ${ }^{* *}$. Así en una Concordia entre el Marqués de Santa Cruz y la Orden de Calatrava sobre la provisión del curato de Valdepeñas, pueblo que ya hemos citado pertenecía a dicho marqués desde 1575-1581, dado que los comendadores de la Orden podían presentar el párroco al Sacro Convento de Calatrava la Nueva, para que el Prior lo confirmará en el cargo, se cita como testigo del marqués a "Do. De Rojas", que posiblemente se refiere al Diego de Rojas que nos ocupa ${ }^{26}$. Más interesante parece la noticia, extraída de un protocolo notarial, que recoge la compra-venta por la cual Diego de Rojas, cristiano nuevo, morador de El Viso, sede del marquesado de Santa Cruz, compra a un vecino de Manzanares, llamado Alfonso de la Cruz, "una mula parda cerrinegra de lomos con sus jamugas" por 63 rs., cantidad que se hace constar paga Diego de Rojas en dos plazos. Es interesante señalar que todas estas señas de identidad coinciden exactamente con las derivadas de la documentación aragonesa para Diego de Rojas, presentándolo como cristiano nuevo, morador de El Viso, que ya hemos citado como propiedad de Santa Cruz, y también el hecho de comprar una mula con jamugas, una silla de tijera con patas curvas y correones que usaban las mujeres para viajar, lo que quizá podría indicarnos su propósito de un próximo casamiento, pues la compra se hace el 6 de febrero de 1591, justamente un año antes de su compromiso matrimonial en tierra zaragozana ${ }^{27}$.

No obstante, la búsqueda de datos sobre la figura de Diego de Rojas no ha concluido y, como ya apunté, sigue siendo hoy uno de los objetivos de nuestra investigación. A este respecto, también me "parece curioso" señalar la coincidencia en nombres y apellidos de quien creemos era un destacado morisco (si no difícilmente podría haber contraído matrimonio con una Compañero) con "otro morisco ¿o quizás el mismo?", que tuvo un papel "crucial" en las alteraciones y posterior desenlace de la rebelión de Las Alpujarras. Me refiero a Diego de Rojas, familiar muy próximo a Don Fernando de Córdoba y Valor, el elegido por los moriscos como rey de las Alpujarras en el levantamiento de 1567-1568. V. Sánchez, al tratar las diferencias entre los dos bandos moriscos en la guerra de Las Alpujarras, menciona la dura persecución de Abén Humeya en las personas de su suegro, Miguel de Rojas, y de su cuñado, Diego de Rojas, y cómo este último y otros moriscos de los depurados en Ojigar por Abén Humeya, siguiendo las directrices de Argel y del capitán turco Caracax, asesinaron a Abén Humeya en septiembre de 1569. De los tres Diegos que participa-

** Deseo expresar mi agradecimiento a la generosa contribución de M.F. Gómez Vozmediano (Sección de Nobleza, Archivo Histórico Nacional Toledo), por la búsqueda y aportación de estos datos.

26. A(rchivo) Dioc(esano) T(oledo), Libro 2088, fol. $693 \mathrm{v}$.

27. A.H. Prov. Ciudad Real, Prot. Not. Leg. 1006/4 , 6, II, 1591. 
ron en el magnicidio del reyezuelo, su cuñado, Diego de Rojas, su secretario, Diego de Arcos y Diego de Alguacil, sólo de este último sabemos que, tras la subida al trono de Muley Abdalla Abén Aboo, salió huyendo como otros muchos importantes moriscos y se exilió en Tetuán ${ }^{28}$.

¿Qué más noticias tenemos sobre este Diego de Rojas de Las Alpujarras? Sabemos que, con otros miembros de su familia, hombres y mujeres, participó muy activamente en la rebelión alpujarreña, lo que les deparó el ser procesados y castigados en el Auto de Fe celebrado en Granada en 1571. Así, entre los castigados en este Auto encontramos a varias mujeres de la destacada familia Rojas, como María de Rojas y las hermanas Catalina, Leonor y Juana de Rojas, algunas ya viudas de altos representantes de la sociedad, como de D. Alonso Hernández de Montalbán, receptor de la Chancillería, o de Jerónimo Nájera, secretario de la misma, y otras jóvenes hijas de algunos de ellos, como Juana, nieta de Don Alonso. También se citan como procesados a Juan de Rojas y a los hermanos Diego y Gaspar de Rojas. La causa de Diego de Rojas recoge: “Diego de Rojas, morisco, hijo de Miguel de Rojas, vecino de Ogijar del Alpujarra, cuñado del primer tirano Don Fernando de Córdova y Valor que levantó los moriscos del Alpujarra... etc.". En ella se le acusa de participar en los levantamiento de Ogijar y de Jubiles y de prácticas de moro, pero estos cargos no le llevaron a la muerte, pues "tras confesar de él y de otros" fue admitido a reconciliación con galeras perpetuas y doscientos azotes. No obstante, esta sentencia no debió de "convencer" a todos, pues en la causa inquisitorial hay una nota marginal que dice "se le deviera de relaxar conforme a lo acordado". Su hermano Gaspar tuvo castigo más leve, pues se le condenó a galeras sólo por tres años. Así, pues, todas estas noticias nos certifican la importancia de Diego de Rojas como pariente político muy próximo al líder de la rebelión. Es más, en esta misma relación de destacados personajes castigados, encontramos citada a Dña. María de Córdoba, "mujer de Don Hernando de Córdoba, el principal caudillo del levantamiento de los moros", acusada de que "en su casa de Jubiles había un alfaquí al que ella y los suyos oían". Esta noticia es interesante, pues señala que tenía casa en Jubiles, uno de los lugares en que se cita estuvo Diego de Rojas haciendo proselitismo entre los suyos, lo que de nuevo parece indicar que esta Da. María era el miembro de la familia Rojas casada con el líder de las Alpujarras y posiblemente hermana de Diego ${ }^{29}$.

Así, pues, todas las noticias nos llevan a señalar la importancia de un Diego de Rojas, activo miembro del levantamiento de las Alpujarras, hijo de Miguel de Rojas, cuñado de D. Fernando de Valor, etc. Nuestra pregunta, todavía no resuelta, es: ¿podría ser este mismo destacado morisco andaluz quien, "arreglado

28. V. SÁnchez RAmOS, «La Guerra dentro de la Guerra: Los bandos moriscos en el alzamiento de Las Alpujarras», VII Simposio Internacional de Mudejarismo, Teruel, 1999, pp. 515-518.

29. A.H.N.M., Sección Inquisición, Leg. 1953, Causas 5, 6, 11, 14 y 28. 
económicamente o por otros medios" su castigo a galeras perpetuas (quizás en galeras a cargo de Bazán, como General de las Galeras de Nápoles), conectase con la familia Santa Cruz y después, por matrimonio, con la familia zaragozana de los Compañero? Nos parece sumamente coincidente el nombre y apellido de ambos y el hecho de que en su acta de matrimonio se cite a Diego de Rojas como hijo de Miguel, dato que coincide con el castigado en el Auto de Fe granadino de 1571 o, como comentaremos más adelante, el hecho de que muchos moriscos granadinos vinieron a vivir a la zona de Valdepeñas y el que él mismo tuviera un esclavo de origen granadino. Han pasado veintiún años hasta la fecha de su boda, 1592, pero ello no tuvo por qué ser óbice para un matrimonio, quizá de edades algo desiguales, ¿o quizás el contador en Valdepeñas del II Marqués de Santa Cruz era un descendiente del Diego de Rojas castigado?

La realidad es que tras la celebración de su matrimonio no hemos encontrado noticias de Diego de Rojas en la documentación consultada, ni de él ni de los posibles hijos habidos en su matrimonio con Cándida Compañero y que creemos no los hubo. Todo conduce a pensar que, como ya apunté, posiblemente, la cláusula de las Capitulaciones que exigía a Diego de Rojas cambiar en seis meses su lugar de residencia, dejar Valdepeñas y venirse a vivir con su esposa a Aragón, no debió de cumplirse. Posiblemente el alto cargo que tenía y los emolumentos y privilegios derivados del mismo, pudieron influir para no iniciar su andadura hacia tierras aragonesas. Una prueba de ello podría ser una noticia de 1593, encontrada en un proceso contra el prior y párroco del maestrazgo calatravo de El Viso, lugar del Marqués de Santa Cruz, en la que encontramos citado a Diego de Rojas, quien ya hemos señalado al comentar la compra de una mula por éste, que residía en este lugar. El proceso contra el prior se debió a que éste expulsó de la parroquia con malos modos, empellones y hasta bofetadas a un esclavo llamado Alonso, que había proferido en el templo palabras afrentosas e irreverentes contra Cristo y contra el culto católico ${ }^{30}$. La resolución del problema en sí no vino derivada de la actuación del párroco ni del esclavo, sino de la personalidad de su dueño. El esclavo, según se hace constar en el documento, era "un morisco granadino de Diego de Rojas, contador de su señoría", es decir del Marqués de Santa Cruz. El evento no fue cosa baladí, pues suscitó un pleito criminal eclesiástico ante el Consejo de la Gobernación del Arzobispado de Toledo que, si bien terminó dándole la razón al sacerdote por defender el nombre de Cristo y el lugar sacro, éste no se libró de ser reconvenido a que no volviese a ser tan vehemente ni violento en lugares sagrados. De la lectura del texto parece deducirse que en todo ello influyó poderosamente la importancia de su amo, e incluso podríamos decir que, para evitar la enemistad del fiel servidor de su patrón (el marqués), el prior excusó la denuncia que podría haberse hecho ante la Inquisición toledana, pues por he-

30. A(rchivo) Dioc(esano) T(oledo), Sección Cofradías, (Sin catalogar), año 1593. 
chos similares (blasfemias, irreverencias, etc.) encontramos en las Relaciones de causas inquisitoriales de otros tribunales a muchos castigados. Estos datos son importantísimos para nuestra investigación, porque una vez más demuestran que Diego de Rojas desempeñaba el cargo de contador del II Marqués de Santa Cruz, era uno de sus conocidos servidores de confianza y hombre económicamente poderoso, pues es sabido que en esta época no era muy corriente entre los moriscos tener esclavos e incluso fue uno de los problemas que se plantearon en el Memorial de Francisco Núñez Muley y en el Sínodo de la Diócesis de Guadix y Baza, pero después de la sublevación de 1568 se calcula que unos 4.000 moriscos y moriscas granadinos fueron esclavizados y debido a ello muchos miembros de la elite morisca compraron esclavos de su mismo origen ${ }^{31}$. Este debió de ser el caso de Diego de Rojas, poderoso morisco granadino que adquirió esclavos también granadinos. Ahora bien, si todo ello avala una vez más la importancia social y económica de Diego de Rojas, lo que es sumamente interesante para nosotros es la fecha del documento, 24 de junio de 1593. Diego de Rojas hizo sus Capitulaciones matrimoniales en Zaragoza en enero de 1592 y en ellas, entre lo pactado "entre partes", hemos visto que se le exige "sea tenido y obligado a venir y que vendrá y habitará en el presente Reino de Aragón, en la presente ciudad de Zaragoza o en aquella ciudad y lugar que le pareciere bien visto en el presente reino" $\mathrm{y}$, lo que no debe olvidarse, es el plazo dado para su cumplimiento, "dentro del tiempo de seis meses, contaderos desde el día de la jura de estos Capítulos". Otra cláusula importante es la promesa de que el contrayente "no sacará a su esposa ni a su hacienda contra su voluntad a vivir fuera del Reino de Aragón", así como el que debe de venir con toda su hacienda y casa y que "vestirá y enjoyará a su esposa". Si las Capitulaciones ante el notario zaragozano Martín Español se firmaron en enero de 1592, el plazo límite fijado para incorporarse a su nueva residencia terminaba en julio de ese mismo año 1592. El documento que recoge el affaire entre el párroco de El Viso y el esclavo de Diego de Rojas se fecha en junio de 1593, es decir, casi un año después de la fecha límite impuesta en el contrato matrimonial. Nuestra pregunta sigue siendo ¿se hizo realidad la cohabitación del matrimonio Rojas-Compañero? ¿Llegó a residir Diego de Rojas en tierras aragonesas? Hasta ahora, documentación de muy distinta tipología no parece contribuir a dar una respuesta afirmativa, sino más bien no encontramos indicios que confirmen su presencia o la de sus descendientes en ellas. Sólo sabemos que en febrero de 1604 Diego de Rojas ya había muerto, pues su esposa consta en esta fecha como viuda, al contraer su segundo matrimonio con Don Alonso Muley Merín Enríquez de Fez y en esas fechas sabemos que era administrador del Estado de Santa Cruz Gaspar de Garnica ${ }^{32}$. Así, pues, nos

31. A. Martín CASARES, «Moriscos propietarios de esclavos y esclavas», VI Simposio Internacional de Mudejarismo, Teruel, 1996, p. 435.

32. J. López-SAlazAr, op. cit., p. 72. 
queda la duda de si la promesa de Diego de Rojas, recogida en sus Capitulaciones matrimoniales con Cándida Compañero, de residir en Aragón se cumplió o fue tan sólo un matrimonio acordado y quizá hecho realidad, pero "a distancia". Tenemos la esperanza de encontrar documentos que den respuesta a nuestras hipótesis y a nuestras preguntas, para conocer no sólo la dura estancia en cárceles y procesos inquisitoriales de Cándida Compañero, sino otros datos sobre su vida en el intervalo temporal de los años 1592, fecha de su primer matrimonio, hasta el año 1604, fecha de su segunda boda, con el destacadísimo morisco Don Alonso Muley y Merín Enríquez, de Fez.

\section{Don Alonso Muley Merín EnRíQuez, de Fez: SEGUNDO ESPOSO DE CÁNDIDA COMPAÑERO-MENOR}

En el Archivo de la zaragozana parroquia de San Pablo encontramos registrada con fecha 16 de febrero del año 1604 el acta matrimonial de Don Alonso Merín y Muley Enríquez, de Fez, con Cándida Compañero, cuya misa nupcial se celebró el 30 de abril de ese mismo año. Los unió en matrimonio el vicario de dicha parroquia, D. Gregorio Andía, sacerdote que ya había casado a la novia en su primer matrimonio y quien, como hemos podido constatar en distintos documentos parroquiales, notariales, inquisitoriales y privados, tuvo una estrecha relación con las familias Compañero y les fue de vital ayuda en momentos clave de sus vidas. Los padrinos del enlace Muley y Merín Enríquez-Compañero Navarro fueron, en primer lugar, el notario zaragozano Pablo Villanueva, que también hemos podido constatar que ejecutó muchos de los documentos de transacciones comerciales de estas familias y recogió las últimas voluntades testamentarias de algunos de sus miembros. En segundo lugar, constan como padrinos el sacerdote de la parroquia de San Pablo mosén Juan Adam y el hermano de la contrayente, el líder de los moriscos aragoneses y también feligrés de esta parroquia, Miguel Enrique Compañero Navarro. Entre los datos del acta se señala que el novio era licenciado y residente en Sevilla, y que la novia, feligresa de la parroquia de San Pablo y residente en Zaragoza, era viuda. De Cándida Compañero conocíamos muchos pasajes de su vida personal y familiar pero, como en el caso de su primer esposo, tampoco teníamos noticias sobre la personalidad de D. Alonso Merín Muley. Por ello, parece oportuno conocer algo más sobre este morisco de procedencia andaluza, con título de licenciado, que viene a desposarse a las lejanas tierras aragonesas y de quien, dada la importancia de la desposada y de su familia, intuimos que debía de ser persona destacada dentro de la sociedad morisca. Los datos que en esta investigación fuimos recopilando confirmaron sobradamente nuestra hipótesis.

La importancia de Alonso Muley Merín Enríquez, de Fez, la vemos reflejada en distintos documentos notariales, en los que se recogen comandas, apocas, débitos de dinero, etc., etc., y, lo que es más singular, en el hecho de que 
de forma unánime se le cita en ellos con el tratamiento de Don y a veces de caballero, lo que parece incidir o coincidir con el origen noble que Rubiera da a las personas que portaban estos "apellidos o sobrenombres"33. Así, en julio del año 1604, con motivo del arriendo por cuatro años del lugar de Purroy (Huesca), del señor Duque de Lerma, hecho por Don Juan Francisco de Subiza, su procurador, a Miguel Enrique Compañero, cuñado de Don Alonso Muley Merín, de nuevo aparece citado éste como Don Alonso Enríquez, junto con Juan Compañero, tío de su esposa, como fiadores de una encomienda en la nada despreciable cantidad de 104.000 sueldos jaqueses. El documento, hecho por el notario zaragozano Martín de Abiego, recoge, como en otros documentos, en una cursiva andaluza perfectamente legible, la firma autógrafa de D. Alonso, ahora tan sólo como D. Alonso Enríquez. Este arriendo sobre el lugar de Purroy lo seguirá teniendo el acaudalado morisco zaragozano Miguel Enrique Compañero el año 1607, según consta por documentación procedente del mismo notario en la que recoge el pago del arriendo al Duque de Lerma, en contestación a una carta y procura que mandó desde Valladolid el procurador de éste, el ya citado D. Juan Francisco de Subiza ${ }^{34}$. En un documento interesante mandado hacer por Cándida Compañero, se califica a ésta como mujer de Don Alonso Merín Enríquez, de "profesión advogado" y domiciliado en Zaragoza, pero residente en Corte (Valladolid?) ${ }^{35}$. El documento hace alusión a una "procura recibida y testificada" hecha en Valladolid el 26 de febrero de 1606 por Hernando de Pina, "escribano del rey, residente en Crimen de su Corte", y en el que Cándida Compañero instituye como procuradores suyos a Miguel Palacio y a Miguel Cortés, mayordomo del Hospital de Gracia de Zaragoza, para que por ella y por su marido puedan demandar, recibir y cobrar de una serie de personas que se nombran y que le deben distintas comandas, hechas ante P. Villanueva (Hernando Ram le debe 810 sueldos, el infanzón Juan Tolosa 3.100 sueldos, los vecinos de Mediana 1.120, Francisco Ruiz 600 sueldos, etc.). El documento lo firman como testigos el escribiente Miguel de las Foyas y Cristóbal Gacti. Este documento, y otros que se recogen tras él, son muy interesantes, pues, en parte, parecen reflejar la voluntad de que se puedan cobrar algunas deudas de Cándida Compañero por su esposo, Don Alonso Merín, y por sus procuradores y, en parte, se refleja también lo que constituirá, como veremos al estudiar otros documentos notariales, la persistencia y quizás última voluntad de Cándida Compañero de beneficiar a determinadas instituciones benéficas zaragozanas, como el Hospital de Nuestra Señora de Gracia y los hospitalicos de niños de esta ciudad. Así, por ejemplo, ese mismo día, Cándida Compañero hizo un documento a favor de los doctores Jaime Arroyo, canóni-

33. M.J. RUBIERA, op. cit.

34. A.H.Not.Z., Notario Martín de Abiego, Legs.1431 y 1435.

35. A.H.Not.Z., Notario Miguel Villanueva, Leg. 286. 
go de la Seo de Zaragoza, Pedro Jerónimo Despes y Juan de Tiermas, infanzones de Zaragoza, como ciudadanos regidores y gobernadores del Hospicio de Nuestra Señora de Gracia, para "utilidad de los pobres huérfanos de 120 sueldos de censal con 2.400 sueldos de propiedad mediante Carta de Gracia". Por el momento no sabemos con exactitud el motivo de que la procura de febrero de 1606 se hiciera en Valladolid, por el escribano real residente en la Sala del Crimen de Corte, pero la larga persecución y años de cárcel sufridos por Cándida Compañero, nos hacen quizás sospechar que, amén de las cárceles de Logroño y Zaragoza, quizás estuviese también encarcelada en Valladolid, aunque no he encontrado constancia documental de ello, o, lo que sí creo bastante más probable, ¿la importancia personal o profesional de su esposo como abogado le hacía residir a éste por esas fechas en Valladolid, ciudad que entonces gozaba de ser la residencia de la Corte, tras su traslado a la misma por orden de Felipe III? Por estas fechas la salud de Cándida Compañero estaba ya muy mermada, pues, aunque ella no aceptaba confirmarlo, tras sus largos años de cárcel, encierros y calamidades personales y familiares, a sus 34 años estaba ya casi ciega, por lo que hay documentos en los que se recoge que no puede firmar porque no veía y en otros ella misma aduce que no firma porque no sabe escribir, aseveración que es totalmente incierta, pues en otros documentos anteriores se recoge su firma perfectamente legible.

Realmente, la trayectoria vital de Cándida Compañero, trazada a través del estudio de distintas fuentes documentales, no puede ser más triste. Su primera noticia, como hemos avanzado, nos la presenta ya huérfana de padre, el acaudalado y notable morisco Enrique Compañero, acompañando a su madre, la riquísima y culta morisca Gracia Navarro, en cárceles inquisitoriales. Tras un largo periplo por distintas cárceles, primero como acompañante y después como desgraciada protagonista, contrajo primeras nupcias a los 21-22 años con un egregio morisco, posiblemente emparentado con la notabilísima familia de los Valor, Diego de Rojas, y, tras enviudar de éste, casó de nuevo, cuando aún no contaba 33 años, con otro miembro de la más rancia aristocracia árabe, Don Alonso Merín y Muley Enríquez de Fez.

La vida de Cándida Compañero Navarro había transcurrido desde la más tierna infancia en la soledad de la orfandad paterna y privada del afecto de su madre, que pasó la mayor parte de su vida, hasta su muerte, en las cárceles inquisitoriales de Logroño y de Zaragoza, cárceles en las que frecuentemente le acompañó su hija o compartió castigos, ya que fue juzgada y procesada a los 16 años, obligada a tornar sus ricos y lujosos vestidos por el hábito vergonzante y castigada duramente por la Inquisición a lo largo de su desgraciada existencia. No obstante, como más adelante demostraremos, posiblemente el evento más afortunado en la vida de Cándida Compañero fue el contraer matrimonio con este posible descendiente de la corona de Fez.

La presencia de Don Alonso en tierras aragonesas, además de en los documentos citados desde 1604 a 1606, se constata de nuevo en otros del año 1607. Así, por ejemplo, se refleja en un documento de este año en el que D. 
Alonso Merín consolida el uso de unas casas sitas en la calle de San Pablo y cuya descripción concuerda con las que sobre las propiedades de su esposa encontramos en otros documentos ya citados. De este mismo año es un documento que comienza: "Yo, Don Alonso Enriquez Muley y Merín de Fez, caballero, domiciliado en la ciudad de Zaragoza...", etc., en el que se recogen noticias sobre una comanda de 10.000 sueldos, heredada de Francisco de Eslava por su mujer, Úrsula Villar del Conde, que la vendió al dicho Don Alonso Merín el 15 de septiembre del año 1606, ante el notario zaragozano Francisco Moles y ahora, en 1607, la vende Don Alonso a Pedro Enrique, pastor, infanzón. Es curioso constatar que el documento viene firmado, y cito textualmente, por "Don Alonso Muley y Merín de Fez y Enríquez" y refrendado por los testigos Pedro de Aguirre y Pablo Lazcaz de Colomina ${ }^{36}$. El hecho de que tanto al comienzo como al final del documento se le cite con el título de Don y se acompañe su nombre con los sobrenombres de Muley, Merín, Enríquez, parece que confirman su origen noble, a la vez que la inclusión "de Fez" señalaría su origen y su procedencia, siguiendo el artículo ya citado de M.J. Rubiera. Por otra parte, el nombre de Alonso no debía de ser raro en la familia Muley, pues A. Martín, en un artículo en el que expone la costumbre de los moriscos ricos de comprar esclavos musulmanes para luego liberarlos, cita cómo Don Fernando Muley tenía un esclavo tunecino, que fue liberado en 1537 y a cuyo pago del rescate y carta de libertad contribuyó un familiar de Don Fernando, llamado (¿casualmente?) Don Alonso Muley. La semejanza de nombres y apellidos con nuestro personaje es digna de tener en cuenta ${ }^{37}$. El 29 de octubre de este mismo año 1607, por un asunto de tributación de 120 sueldos anuales de unas casas suyas, "sitas en la parroquia de San Pablo", que deduzco formaban parte de las casas propiedad de su esposa ya citadas, comparece de nuevo Don Alonso Merín ante el notario zaragozano Martín de Abiego y es interesante señalar que el notario lo califica en el documento como "el muy magnífico Don Alonso Merín Enríquez, Doctor en Derecho"38.

Con fecha 1 de octubre de 1609, encontramos un documento del notario Francisco Moles en el que consta que Diego Mendoza, mercader vecino de Zaragoza, como procurador de Cándida Compañero, mujer de Don Alonso Merín, domiciliados en Zaragoza, y como procurador de su marido el dicho Don Alonso Merín, constituido y sustituidos, mediante constitución y sustitución fechada en el Palacio de la Aljafería del Santo Oficio de la Inquisición del Reino de Aragón y de esta ciudad a 7 de enero de 1608 por Juan de Borau, habitante de Zaragoza y por autoridad real por los reinos de Aragón y Valencia notario público, testifica haber recibido de varios vecinos de Gelsa la cantidad

36. A.H.Not.Z., Notario Pablo Villanueva, Leg. 102, año 1607.

37. A. Martín, op. cit., pp. 433-435.

38. A.H.Not.Z., Notario Martín de Abiego, Leg. 43. 
de 500 sueldos en parte de pago de una comanda ${ }^{39}$. Es interesante destacar que el documento notarial hace mención a un documento hecho en el Palacio de la Aljafería de Zaragoza, donde se ubicaba por aquellos años la cárcel de la Inquisición zaragozana, lo que nos hace deducir que en 1608 la esposa de Don Alonso, Cándida Compañero, se encontraba de nuevo por esas fechas presa por la Inquisición, y que la testificación del documento la hace el secretario del Santo Oficio y notario, Juan Borau, que vivía en la Calle de la Vitoria, no lejos de Cándida Compañero y que, como ella, era feligrés de la parroquia de San Pablo. Por otra parte, nos consta documentalmente que Borau tuvo diferentes contactos con la presa a lo largo de su complicada vida, incluso hemos visto que fue uno de los testigos de su primer matrimonio, y sabemos que le ayudó en determinados momentos de su vida. Además, por su testamento, recogido también por el notario Francisco Moles en junio de este mismo año, deducimos que estaba familiarmente relacionado con los Andía y un Andía, Gregorio de Andía, era el peculiar vicario de la parroquia de San Pablo que casó a Cándida y a otros Compañero y ayudó de forma muy destacada a ésta y a su familia, así como también a otras determinadas familias moriscas ${ }^{40}$. Mucho debió de suponer para algunas de ellas, pues en diferentes documentos notariales nos consta la elección de Gregorio de Andía como procurador y cuidador de los niños moriscos cuyos padres estaban castigados por la Inquisición, tribunal del que él mismo sufrió también "penalizaciones de matiz político" tras las alteraciones aragonesas de 1591-1592 ${ }^{41}$.

La vida de la esposa del magnífico don Alonso Merín y Muley de Fez, por estos primeros años del siglo XVII, seguía siendo no muy halagüeña, debido a la persistencia con que la Inquisición seguía teniendo en el punto de mira a Cándida Compañero. Recordemos que ya en el Auto de Fe celebrado en Zaragoza el 8 de junio de 1587, cuando su madre seguía presa en la "cárcel perpetua inquisitorial" de Logroño, encabezó la lista de "moriscas reconciliadas por errores de la secta de Mahoma" y, tras haber reconocido practicar ceremonias de moros, al acabar el Auto, se le quitó el hábito, en atención a que "tenía diez años cuando fue instruida por sus padres y tíos" ${ }^{\prime 2}$. Ahora, tras sus dos matrimonios y sufrir la lenta agonía de ir viendo "desaparecer" en las cárceles y en la hoguera a sus familiares y amigos, volverá a sufrir en ella misma el peso de la Inquisición. En 1608, tan sólo unos meses después de ver "relaxar" y morir a su único hermano y a su joven esposa, y aceptar la tutela de sus cinco pequeños

39. A.H.Not.Z., Notario Francisco Moles, Leg. 1093, año 1609.

40. ibidem, pp. 1133-1136.

41. M.C. ANSÓN CALVO, «La actividad inquisitorial aragonesa en el reinado de Felipe II y su repercusión en los súbditos moriscos», en J. Martínez Millán (ed.), Felipe II (1527-1598) Europa dividida: La monarquía católica de Felipe II, tomo III, pp. 11-36.

42. A.H.N.M., Sección Inquisición, Libro 989, fol. 299 v. 
sobrinos huérfanos, se reanuda con más intensidad para ella y los suyos la persecución inquisitorial ${ }^{43}$. Así, en la relación de causas despachadas en el Auto de Fe celebrado en Zaragoza el 16 de noviembre de 1609, uno de los Autos más agresivos, desde el punto de vista cuantitativo, por el elevado número de mujeres moriscas castigadas, en la lista de los que van a relajarse en persona, ocupa el segundo lugar su tía Ana Navarro y el tercer lugar la misma Cándida Compañero $^{44}$. Se le cita como "nueva convertida, mujer de Don Alonso Merín, morisco de Fez, vecinos de Zaragoza, de edad de 37 años", que ya había sido reconciliada en 1587 por vivir como mora y que en el año 1608 fue testificada por muchos testigos de haber hecho ritos y ceremonias de moros por una morisca difunta, con otros de su casta y generación. Se recuerda que estuvo presa por ello y negó todo, por lo que, concluida su causa, fue mandada relaxar a la justicia y brazo seglar "como negativa convencida e impenitente relapsa", con confiscación de bienes ${ }^{45}$... La persecución continuó y, así, en la Relación de causas despachadas por la Inquisición aragonesa desde el Auto de noviembre de 1609 hasta noviembre de 1610, encontramos de nuevo, con el número 31 la causa de Cándida Compañero, que ocupa a su vez el primer lugar entre las mujeres que deben relajarse por mora. Se le inscribe como "morisca, de 37 años, vecina de Zaragoza, mujer de Don Alonso Merín Enríquez, morisco de Fez", y se recuerda que ya cuando contaba once años fue testificada de que vivía como mora y que a los dieciocho años fue reconciliada en el Auto de Fe celebrado en junio de 1587, recordando de nuevo que en febrero de 1608 murió Esperanza Granada, familiar de su hermano Miguel Enrique, en cuya casa, según testificaron distintos testigos, se le amortajó como mora y se le rezaron azoras de moros. La rea, en la primera, segunda y tercera audiencia, negó todas las acusaciones, pero los testigos se ratificaron en sus declaraciones y ella en sus negaciones, por lo que fue votada a relajación en Auto Público, con confiscaciones de bienes, como "negativa convencida impenitente relapsa", puesta a tormento in caput alienum y preparada para que se hiciese justicia; pero, sorprendentemente, Cándida Compañero-menor, tras confesar, pidió ser absuelta y se deliberó que, de momento, se sobreseyese la sentencia de relajación. Después se tuvo otra audiencia con la rea en la que se leyó su confesión y ella se ratificó en la misma, con lo que se concluyó su causa con acuerdo de su letrado, pero vuelta a ver en consulta se determinó que se hiciese sentencia "como a impenitente relapsa y vista por VS. Merced fuese admitida a relaxación con hábito y cárcel

43. A.P.S.P.Z., Banco de Datos particular de Actas Sacramentales y A.H.N.M., Sección Inquisición, Libro 989 a 991.

44. M.C. ANSÓN CALVO, «Poder social, poder económico y persecución: variables significativas en algunos procesos inquisitoriales aragoneses», Actas IV Reunión Científica de la Asociación Española de Historia Moderna, Tomo II, Disidencias y Exilios en la España Moderna, Alicante, 1997, pp. 193-212 y A.H.N.M., Sección Inquisición, Libro 990 a 991.

45. A.H.N.M., Sección Inquisición, Libro 990, fols. 641-642. 
perpetua". Es decir, Cándida Compañero, según las noticias vertidas en los primeros folios del Libro 991 de Relaciones de Causas Inquisitoriales ${ }^{46}$, parece que se había librado de la muerte, pero seguía privada de libertad y portando el hábito vergonzante con el que había "estrenado" las mieles de la adolescencia, cuando acompañaba a su madre en la cárcel inquisitorial logroñesa. Ahora bien, una minuciosa lectura del resto del libro nos permite conocer más detalles sobre la triste situación de Cándida Compañero. Así, en la Relación de personas que la Inquisición aragonesa mandó salir en el Auto Público de Fe de 16 de noviembre de 1609 y de las causas despachadas en la Sala del secreto, entre los relaxados por moros, encontramos con el número tres, tras su tía Ana Navarro, a Cándida Compañero, mujer de Don Alonso Merín, morisco de Fez ${ }^{47}$. Las acusaciones vertidas por varios testigos son las mismas que señalamos en el párrafo anterior, recordando su reconciliación en 1587, haciendo especial énfasis en su participación en amortajar "con camisa nueva, greguescillos de lienzo y toca de viuda" a una morisca en casa de su hermano Miguel Enrique Compañero, así como el haber rezado azoras y hacer la zala. Muy grave fue la acusación de un testigo que dijo había recibido de Cándida 100 reales para que, cuando su hermano estaba preso por el Santo Oficio, no dijese que le había visto hacer a éste ceremonias de moros. Todo lo negó la acusada y tachó a tres de los testigos de enemigos suyos, pero fue condenada a salir en el Auto de Fe con insignias de relajada, serlo por la justicia seglar y confiscarle sus bienes como negativa, convencida impenitente relapsa y a sufrir tormento de la garrucha in caput alienum en el que siguió negando y al final se anota "executóse la relaxación".

Ahora bien, éste es el texto formal de la causa, pero en el margen de este texto hay una nota escrita con letra pequeñísima y casi ilegible que dice: "esta rea pidió audiencia en la mañana del Auto y confesado vivir como mora cuatro años y hecho ritos y ceremonias de moros con creencia y pertinacia después de su reconciliación y satisfizo a las testificaciones y vista en consulta se suspendió la execución de la sentencia de relaxación por agora como V. SA. lo ordenó en el Auto de vista de esta ciudad". Esta nota me llevó a buscar más datos en otros legajos y libros que aportan informaciones inquisitoriales. Así, pude encontrar la noticia de una "oportuna" carta del Consejo de su Majestad, enviada a la Inquisición de Aragón, que notifica que se ha visto el proceso contra Cándida Compañero y se pide al tribunal zaragozano que se haga justicia, pero se haga la concesión de si la rea confesase en el tormento in caput alienum y satisfaciese, se volviese a votar y "siendo del parecer que se relaxase, la relaxia no se executase sin consultar a Madrid" ${ }^{48}$. Es decir, todo parece indicar que había algún hilo conductor que intentaba evitar la relajación de Cándida Com-

46. A.H.N.M., Sección Inquisición, Libro 991, fols. 23 a 25.

47. Ibídem, fol. 94 .

48. A.H.N.M., Sección Inquisición, Leg. 333, fol. 11. 
pañero, $\mathrm{o}$, al menos, ayudaba a que no se llevase a término su triste final. ¿Pesaría la destacada personalidad de su esposo? Lo cierto es que "alguien muy importante" debió de influir en Madrid y en los miembros del Tribunal inquisitorial zaragozano y, sobre todo, en el ánimo y obstinación de la rea, porque, aunque el proceso continuó y Cándida sufrió el tormento in caput alienum de la garrucha y siguió negando, en la mañana del Auto de 16 de noviembre de 1609, Cándida pidió audiencia y cambió su negación por la confesión de haber vivido como mora después de su reconciliación durante cuatro años, haber hecho ceremonias de la secta de Mahoma, e incluso nombró a las personas con quien las había compartido. Posiblemente se le habían hecho llegar noticias por las que era consciente de la total indefensión de ella y de los suyos y conocía el triste final que estaban teniendo casi todos los miembros de su familia y sus más allegados, presos o ejecutados, por lo que su confesión, ahora, poco o nada podía ya influir en sus desgraciadas vidas.

Las noticias dadas parecen conducirnos a la deducción de una "intervención" poderosa en el proceso de Cándida Compañero, intervención que "aconsejó" el cambio de actitud de la rea y su confesión, cambio y actuación que debió de ser el pacto y la condición sine qua non para que el alto tribunal flexibilizase hasta llegar a una determinación nada frecuente, como fue la suspensión de la sentencia de relajación, de la que ya no encontramos más noticias en los Libros siguientes de Relaciones de causas inquisitoriales, pero sí en la consulta de los Legajos de estos años, que recogen en parte consultas y correspondencia entre el Tribunal inquisitorial zaragozano y el Tribunal central de Madrid. Así, entre otras respuestas enviadas de Madrid a Zaragoza, encontramos una fechada en Madrid a 25 de mayo de 1610 y firmada por Azevedo Valdés, que da noticia de que "aquí se ha visto el proceso de Cándida Compañero, presa en las cárceles" y se devuelve con lo acordado en Madrid, rogando que en esta causa y en todas las de nuevos convertidos se proceda con la mayor brevedad. No encontramos más datos explícitamente sobre este asunto, pero en el folio siguiente a este escrito se recoge la recomendación del tribunal central al de Zaragoza, fechada en Madrid el 28 de mayo de1610 (víspera de hacerse público el Bando de Expulsión en Zaragoza) y firmada también por Márquez Azevedo, de que dejen "irse" a los moriscos que están en las cárceles y que puedan hacerlo sin hábito ${ }^{49}$. La realidad es que algunos datos documentales nos llevan a deducir que Cándida Compañero se libró de la relajación, pues la encontramos citada en distintos documentos notariales hechos en los meses de junio y julio de 1610, es decir, poco después de publicarse el edicto de expulsión para los moriscos aragoneses, el 29 de mayo de $1610^{50}$. A este respecto es interesante señalar que en un documento notarial de 31 de julio de 1610, en

49. A.H.N.M., Sección Inquisición, Leg. 333, fols. 64-66.

50. A.H.Not.Z., Notario Pablo Villanueva, leg. 106, año 1610. 
el que se hace alusión a un legado de 1.000 sueldos jaqueses de renta anual, dejado en el testamento de su perseguido tío, Juan Compañero, para casar huérfanas y parientes suyos, y del que nombró como patronos a su mujer Ana Navarro y a sus sobrinos Miguel Enrique y Cándida Compañero, esta última señala "que sólo ella está viva, al haber muerto por la Inquisición sus tíos y su hermano" y "atendido que su Majestad manda que los moriscos convertidos salgamos de sus Reinos de España y que habiendo de cumplir lo mandado, no pudiendo estar en la presente ciudad para cumplir dicho legado y por no tener la vida cierta", queriendo prevenir lo venidero para ahora y después de fenecidos sus días, nombra como patronos del dicho legado a Jerónimo Gómez, vecino de Zaragoza, y al tantas veces citado en los asuntos y documentos de moriscos zaragozanos, D. Gregorio de Andía, vicario de la parroquia de San Pablo. Cándida Compañero, consciente de que por la expulsión puedan no quedar cristianos nuevos para aprovecharse del legado, expresa su voluntad de que, si no los hubiera, pase dicho legado a mujeres y huérfanas pobres, para su matrimonio, y nuevamente nos da una noticia, que ya conocíamos por la documentación y hasta por la literatura de la época al expresar que "dado que los hijos de su hermano están ausentes de los reinos de España" (luego ella conocía que los únicos supervivientes de su familia, habían salido con la expulsión), da poderes a J. Gómez y a G. de Andía para la administración de dicho legado. Los sobrinos de Cándida Compañero, Miguel Enrique, Gabriel, Ana, Francisca y María Lupercia, hijos de Miguel E. Compañero y Esperanza Granada, relajados y muertos en Zaragoza en un Auto de Fe en 1608, y cuyas actas de bautismos hemos encontrado, partieron de España desde el pueblo aragonés de Épila con su abuelo materno, Jerónimo Granada, formando parte de la caravana de moriscos expulsados en mayo de 1610 y según algunas noticias sobre los moriscos expulsados parece que eligieron Túnez como su segunda patria. De Miguel Enrique, nos da noticias Míkel de Epalza, pero de sus cuatro hermanos, que en el momento del exilio tenían entre tres y siete años de edad, hasta el momento no conocemos la suerte que pudieron correr tras el exilio ${ }^{51}$. Cándida Compañero Navarro, siguiendo la misma línea de manifestar su voluntad de donación a centros benéficos, como al Hospital de Nuestra Señora de Gracia de Zaragoza o a las iglesias zaragozanas de La Seo o de San Pablo, encontramos este testimonio en distintos documentos notariales de estos años ${ }^{52}$.

51. P. Aznar Cardona, Expulsión justificada de los moriscos, Huesca, 1612; M. de GuAdalajara, Memorable expulsión y justísimo destierro de los moriscos de España, Pamplona, 1613; M.C. ANsóN CALVO, «Los moriscos de Aragón vistos por un escritor aragonés del siglo XVII», Symposium International d'études Morisques. Images des Morisques dans la Littérature et les Arts, Zaghouan, Túnez, 1997, pp. 25-55; M. de EPALZA, «Moriscos y andalusíes en Túnez durante el siglo XVII», Al-Andalus, XXXIV, fasc. 2 (1969), pp. 248-327.

52. A.H.Not.Z., Notario Miguel Villanueva, Leg. 286, año 1610. 


\section{CÁndida Compañero NaVArRo ANTE El EVENTO DE LA EXPULSIÓN DE LOS MORISCOS}

Como conclusión a esta breve aportación sobre los esposos de Cándida Compañero y sobre ella misma, quizá sería conveniente comentar que todo parece indicar que Cándida Compañero tuvo, al final de su desgraciada y complicada vida, la protección de alguna persona poderosa e influyente que "llegó" hasta los más altos representantes del poder y quizá debido a esta poderosa influencia se salvó de la relajación y de la muerte. Esta percepción se debe a que, de otros moriscos zaragozanos o residentes en Zaragoza, que sufrieron la relajación y la muerte en los últimos Autos de Fe celebrados en Zaragoza, y en especial los castigados como ella entre los años1609-1610, encuentro sus actas de defunción en distintos libros parroquiales. Así, por ejemplo, encontramos el acta de defunción de su tía materna Ana Navarro (la morisca que le precede en la relación de reas), que fue castigada como ella en el Auto de Fe celebrado en Zaragoza el 16 de noviembre de 1609, y de la que también conocemos su testamento, hecho en los momentos previos a su muerte y de la que ya en el mismo nos da "noticia". También nos consta el castigo y posterior muerte en la cárcel de otro reo participante en este Auto, el importantísimo morisco torrellano, Gaspar Zaydejos. Este morisco fue gran amigo y valedor de otros miembros de la familia Compañero, en especial de su tía, Cándida Compañeromayor, y al que tanto favoreció en su, "al fin", localizado testamento, que también fue procesado en el Auto de Fe zaragozano de 16 de noviembre de 1609 y cuya defunción hemos localizado entre las actas de difuntos de la parroquia de San Pablo, situada en la zona urbana donde solían celebrarse los Autos de Fe en Zaragoza, en la Plaza del Mercado ${ }^{53}$.

Así, pues, las informaciones extraídas de la documentación inquisitorial y notarial y el hecho de no tener noticias de Cándida Compañero-menor en las actas de defunción de la parroquia de San Pablo a la que pertenecía y sí de otros castigados en el Auto de Fe de 1609, inciden nuevamente en llevarnos a pensar que tuvo un valedor importante que pudo librarle del último de los castigos inquisitoriales. Posiblemente su valedor fue su segundo esposo, Don Alonso Merín Muley Enríquez, destacado doctor en leyes, como se le cita en distintos documentos, o "advogado", a veces residente en la Corte, según otros, morisco de Fez, y por una parte posiblemente descendiente de la egregia familia de los Muley, de Yusuf ben Názar, fundador de la dinastía musulmana que reinó en Granada de los siglos XIII al XV, conocido como Muley Hacen o Muley Baudili, así como también, por otra parte, descendiente del último Meriní, el sultán 'Abd al Haqq ibn Abí Sa'íd, cuyo poder acabó en la revolución habida en

53. M.C. Ansón CALVO, «Gaspar Zaydejos: destacado morisco aragonés», Turiaso, XVI, 44 (20012002), pp. 233-263. 
Fez en 1465. Si esto es así, no puede dudarse de que el elegido como segundo esposo de Cándida Compañero Navarro, D. Alonso Merín y Muley Enríquez, de Fez, no pudo tener orígenes de más alta alcurnia y que podemos considerarlo como un egregio personaje. También la elegida para esposa todo parece indicar que era persona de la más alta consideración en la comunidad morisca de su tiempo y por ello no puede extrañar demasiado que, a pesar de la distancia, viniera este importantísimo morisco desde tierras andaluzas (¿Sevilla?) hasta el Reino de Aragón, para desposarse el año 1604 con una de las más acaudaladas e importantes moriscas zaragozanas, a residir en la Plaza de la Alfóndiga, de la zona urbana de la Morería de la parroquia de San Pablo, en una de las casas más lujosas y espaciosas de la ciudad y desde la que fue testigo de la implacable persecución inquisitorial que su esposa y los suyos sufrieron hasta el momento de la expulsión de los moriscos aragoneses, decretada por Felipe III en la aciaga primavera de 1610.

\title{
RESUMEN
}

Cándida Compañero, la última representante de la poderosa familia morisca zaragozana, contrajo matrimonio en dos ocasiones. En ambos casos el marido parece provenir de acaudaladas familias moriscas granadinas $\mathrm{y}$, en el caso del segundo, Alonso Muley Enríquez y Merín de Fez, de la más noble familia morisca entre ellas. Su caso, extraído de documentación inédita, podría ejemplificar una cierta colaboración entre elites moriscas de distintas zonas.

Palabras clave: moriscos, Zaragoza, Granada, matrimonios, elites.

\begin{abstract}
Cándida Compañero, the last representative of this powerful Moorish family from Zaragoza, married twice. In both cases the husband seems to come from wealthy Moorish families from Granada and, for the second, Alonso Muley Enríquez and Merín of Fez, from the most noble Moorish family among them. Her case extracted from unpublished documentation, might exemplify a certain collaboration between Moorish elites of different zones.
\end{abstract}

Key words: moriscos, Zaragoza, Granada, marriages, elites. 